\title{
Convergence and divergence of life expectancy in Europe: a centennial view
}

\author{
Johan P. Mackenbach
}

Received: 26 July 2012/ Accepted: 5 November 2012/Published online: 27 November 2012

(C) Springer Science+Business Media Dordrecht 2012

\begin{abstract}
It has been noted that national life expectancies have diverged in Europe in recent decades, but it is unknown how these recent trends compare to longer term developments. Data on life expectancy, cause-specific mortality and determinants of mortality were extracted from harmonized international data-bases. Variation was quantified with the inter-quartile range, and the contribution of changing economic conditions was analyzed by comparing observed life expectancy variations with those expected on the basis of changes in levels of national income and/or changes in the relation between national income and life expectancy. During the first decades of the $20^{\text {th }}$ century, variation in life expectancy in Europe increased to reach peak values around 1920, then decreased to reach its lowest values in 1960 (among men) and 1970 (among women), and finally increased strongly again. The first widening was due to less rapid decline in mortality in Southern and Central and Eastern Europe, particularly from infectious diseases, and coincided with an increasing strength of the national income-life expectancy relation. The second widening was due to stagnating or increasing mortality in Central and Eastern Europe, particularly from cardiovascular diseases, and coincided with a very strong rise of betweencountry differences in national income. Despite some similarities, differences between both episodes of widening differences in life expectancy cast doubt on the idea that the current episode of widening represents a simple delay of epidemiological transitions. Instead, it is an alarming phenomenon that should be a main focus of European policy making.
\end{abstract}

J. P. Mackenbach ( $\square)$

Department of Public Health, Erasmus MC,

P.O. Box 2040, 3000 CA Rotterdam, The Netherlands

e-mail: j.mackenbach@erasmusmc.nl
Keywords Life expectancy $\cdot$ Mortality $\cdot$ Europe $\cdot$ History · Epidemiologic transition

\section{Introduction}

During the 20th century, life expectancy in Europe has risen strongly, but with important variations in both time and space. In Fig. 1 we have plotted all available national life expectancies in a single graph, leaving out the two main 'mortality crises' of 1914-1919 (caused by World War I and an influenza pandemic) and 1940-1945 (World War II). Apart from a steady rise in life expectancy we see some major local interruptions (e.g. in the 1930s, caused by Stalin's collectivization of agriculture in Ukraine and Russia [1] and by the Spanish Civil War [2]), and a clear dispersion in recent decades.

This recent divergence, which is mainly due to stagnation and sometimes decline of life expectancy in Central and Eastern Europe, has not gone unnoticed [3-7]. Studies have shown that recent unfavorable mortality trends in Central and Eastern Europe are largely due to unfavorable trends in mortality from cardiovascular diseases, caused by various circumstances linked to the political and economic situation in the communist and post-communist era, such as dietary problems, excessive alcohol consumption, lack of access to adequate health care, unemployment, poverty and psychosocial stress [8-12].

It is unknown, however, how these recent trends compare to longer term developments in life expectancy. As Fig. 1 suggests, this may not be the first episode of widening of the life expectancy gap in Europe. As will be more fully demonstrated later, an earlier episode occurred in the first decades of the 20th century. Is the current widening more or 

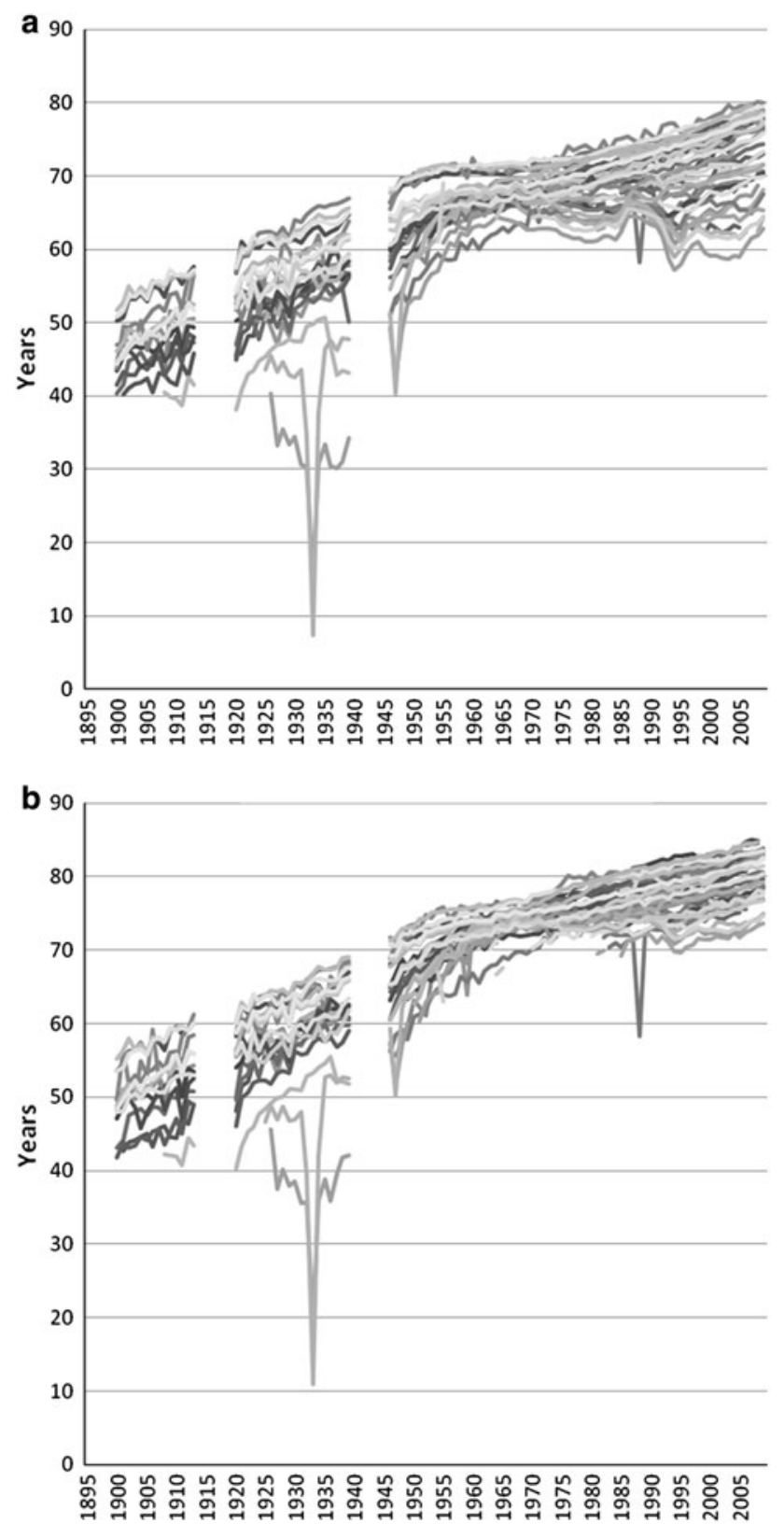

Fig. 1 Life expectancy trends in Europe, 1900-2008, by gender a Men b Women

less severe than the earlier one? Did it have the same causes? Is there a general explanation that can account for both episodes of widening?

The concept that is most often used to explain longterm trends in mortality is that of the 'epidemiologic transition'. This relates trends in mortality to socioeconomic and other developments which bring both health benefits and new health risks [13, 14]. During the epidemiologic transition, which in different parts of Europe began between 1850 and 1920 [15], mortality declined precipitously and life expectancy rose in a spectacular manner, often in parallel with economic growth. What we generally see is rapid growth of life expectancy until about 1950-1970, followed by a few decades of stagnation, and then renewed growth of life expectancy starting in the period 1970-1990 (Fig. 1).

This sequence of growth, stagnation and renewed growth of life expectancy corresponds with three successive stages of epidemiologic transition. During the age of 'receding pandemics' life expectancy rises due to declining infectious disease mortality. This is followed by the age of 'degenerative and man-made diseases', during which life expectancy stagnates due to rising mortality from cardiovascular diseases, various cancers and road traffic injuries [13]. The rise of these 'diseases of affluence' is often seen as a negative side-effect of the economic growth that helped to reduce infectious disease mortality $[16,17]$. Finally, a 'fourth stage' sets in during which life expectancy rises again, mainly due to declining mortality from cardiovascular diseases [18].

It has been argued that rapid declines in mortality are often accompanied by growing disparities, e.g. between countries, regions within the same country, or socioeconomic groups, and that the recent divergence of mortality and life expectancy trends in Europe is simply to be expected as a corollary of the latest stage in the epidemiologic transition [19, 20]. The reason is that innovations which reduce mortality are usually first implemented in some countries and then slowly diffuse to others [21]. This is an appealing notion, but it carries the risk that diverging life expectancy is seen as a 'normal' phenomenon that will inevitably disappear when a natural process of diffusion is allowed to continue.

Empirical evidence for the idea that divergence accompanies mortality decline, spanning both episodes of divergence of life expectancy during the 20th century, is scarce. Therefore, the aims of this paper are:

- to quantify variation in life expectancy in Europe over the whole period 1900-2008, and to systematically compare tendencies of convergence and divergence over time;

- to assess whether the two episodes of divergence in life expectancy coincided with rapid but differential declines of mortality from infectious diseases and cardiovascular diseases, respectively;

- and to assess whether the two episodes of divergence in life expectancy coincided with similar socioeconomic developments, e.g. rapid rises in national income and/or rising variations in national income.

Where available data permit, the analyses will cover the whole of Europe, not the European Union only. 


\section{Data and methods}

Because our analysis aimed at understanding the recent widening of the gap in life expectancy, we decided to retrospectively collect data for all currently existing states in Europe, ignoring changes in the political map of Europe during the 20th century. We defined Europe as the WHO European region, minus Central Asia and Turkey, minus mini-states like Monaco. Because this implied that we would treat the constituent parts of the former Yugoslavia and Soviet Union as separate units we also divided the United Kingdom in 3 constituent parts (England \& Wales, Scotland and Northern Ireland). This gave us more than 40 national units from all over Europe to work with.

Because data for the earlier part of the 20th century were available for a limited number of countries only, with limited representation of Central and Eastern Europe, we present some of the analyses for two sets of countries: the whole of Europe (all available countries) and Western Europe only. In order to reduce the amount of material to be presented, most of the analyses use data for selected points in time (i.e., 1900, 1910, 1920, 1939, 1950, 1960, 1970, 1980, 1990, 2000, 2008). We ignored the years coinciding with both World Wars, and for the same reason we chose the year 1939 instead of 1940 when we restricted the analysis to selected points in time.

For each of the national units, and for their predecessors in earlier times, we collected data on life expectancy at birth, by gender, for the period 1900-2008. Although more recent data were available for some countries, we decided to take 2008 , for which data were nearly complete, as the last year of the analysis. The primary source of life expectancy data has been the Human Life table Database (www.lifetable.de), and this was supplemented by the World Health Organization Health for All Database (http:// data.euro.who.int/hfadb/), the United Nations Demographic Yearbook Historical Supplement, 1948-1997 (http://unstats. un.org/unsd/demographic/products/dyb/DYBHist/HistTab 09a.pdf), the Meslé Vallin Data Base [22] and various other sources [1, 23, 24]. These life expectancy values cover whole national populations and have very narrow confidence intervals, and we have therefore refrained from performing statistical tests.

In order to quantify the magnitude of variations between countries we tried various measures of dispersion (e.g., range, standard deviation, standard deviation/average, inter-quartile range, inter-quartile range/median). Because the inter-quartile range is least sensitive to outliers and proved to be robust even when the number of countries was relatively small, we present results based on this measure.

We also collected data on mortality by cause of death. For the pre-1970 period age-standardized mortality data were extracted from a compendium of International
Mortality Statistics [25]. Because these data were presented in the form of Standardized Mortality Ratios, we re-calculated them as age-standardized mortality rates in order to be able to make a direct comparison with data for other periods. For the analysis of the 1970-2008 period agestandardized mortality data were extracted from the World Health Organization Health for All Database (http:// data.euro.who.int/hfadb/). ICD-code numbers are given in the Appendix.

Data on national income per head of population were extracted from the dataset on Statistics of World Population, GDP and Per Capita GDP, 1-2008 (http://www.ggdc.net/ MADDISON/oriindex.htm). In contrast to other datasets, such as the Penn World Tables, this dataset is comprehensive in its coverage across time and space, and therefore provided us with data on national income for almost all European countries and the whole of the 20th century. The national estimates of Gross Domestic Product per head of population in this dataset are based on extensive harmonization efforts and on a conversion into 1990 International Geary-Khamis dollars using multilateral Purchasing Power Parities. A more detailed explanation of these data has been published elsewhere [26].

In order to analyze the role of socioeconomic development in convergence and divergence of life expectancy, we regressed life expectancy on Gross Domestic Product for each of the selected points in time (i.e., 1900, 1910, 1920, 1939, 1950, 1960, 1970, 1980, 1990, 2000, 2008). We used ordinary least squares linear regression, because the relation between national income and life expectancy was linear within the range of values observed at each point in time. We then used the regression parameters (i.e., intercept and slope) to calculate each country's expected life expectancy in three ways: [1] as expected on the basis of its GDP and the GDP_-life expectancy relationship as found at that point in time; [2] as expected on the basis of its current GDP and the GDP_life expectancy relationship as found in 1950; and [3] as expected on the basis of its GDP in 1950 and the current GDP_-life expectancy relationship. This procedure, which was inspired by Preston's seminal work on the impact of economic development on life expectancy [27, 28], allowed us to assess to what extent convergence and divergence of life expectancy followed convergence and divergence of national income, or changes in the relation between national income and life expectancy.

\section{Results}

The patterns of convergence and divergence observed in Fig. 1 are confirmed by the quantitative analysis presented in Table 1. During the first decades of the 20th century, the 


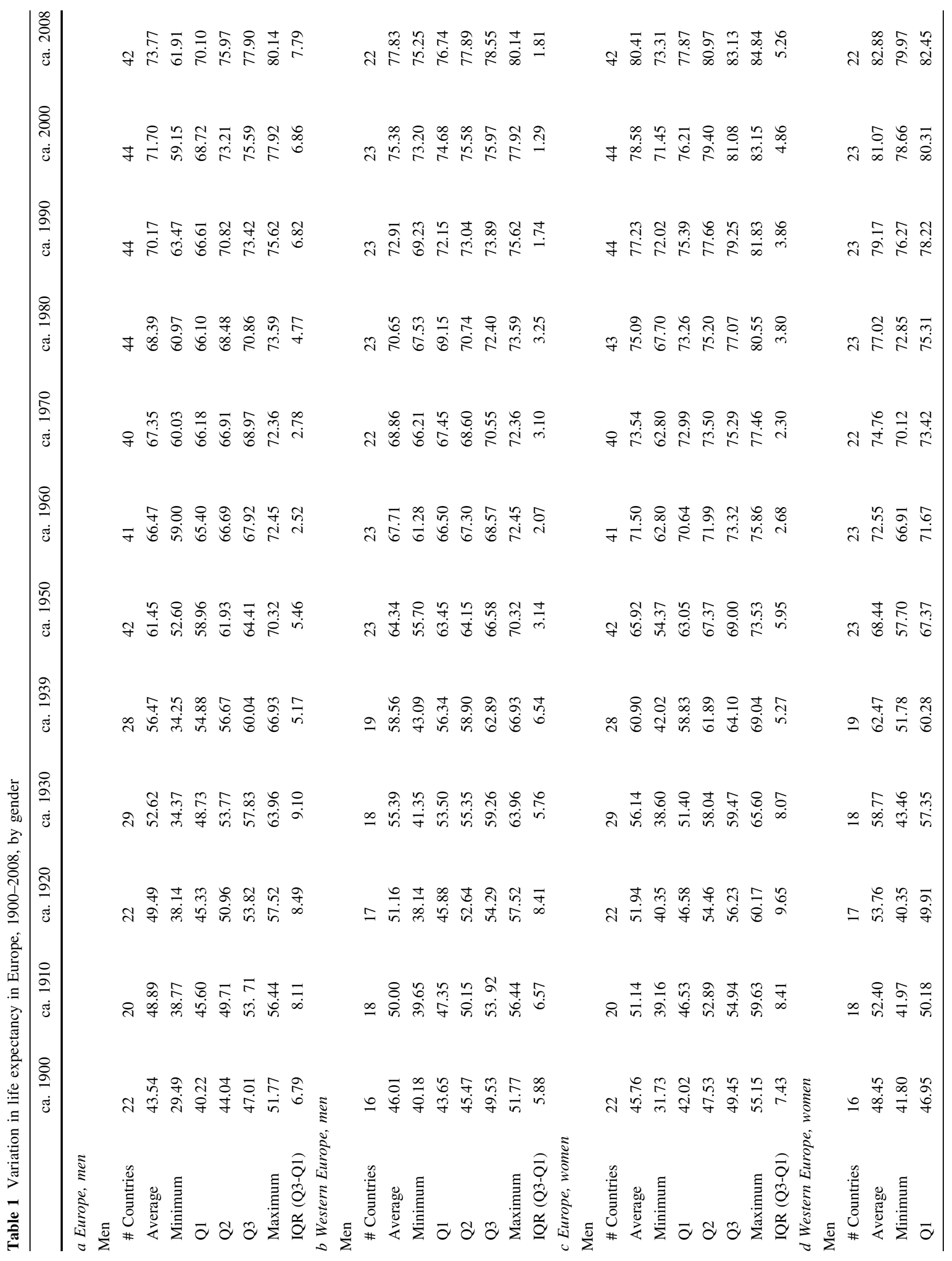




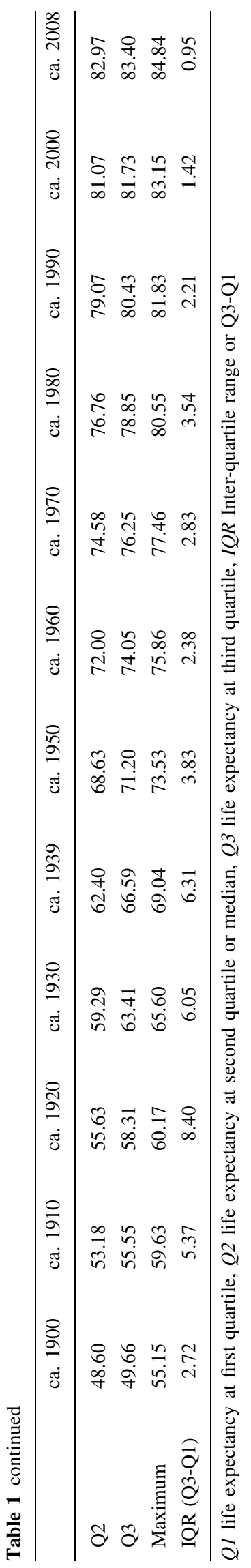

inter-quartile range of life expectancy in Europe rose substantially, and then declined to reach its lowest values in 1960 (among men) and 1970 (among women). After that, however, it started to increase again, to reach values in 2008 that were similar to those seen before World War II. As mentioned in the Introduction, developments before World War II were partly determined by extraordinary events in Russia, Ukraine, and Spain occurring during the 1930s. We therefore repeated the analysis without these three countries, and found that for both men and women the inter-quartile range of life expectancy reached its highest value in 1920, rising from 6.33 in 1900 to 8.23 in 1920 among men, and from 6.55 in 1900 to 8.14 in 1920 among women (results not shown). When we restrict the analysis to Western Europe only, we see that the first episode of widening also occurred in this part of the subcontinent, again with peak values for the inter-quartile range in 1920, but that the second did not (women) or only to a limited extent (men) (Table 1). This implies that the most recent episode of widening is almost entirely due to developments in Central and Eastern Europe.

Figures $2 \mathrm{a}-\mathrm{d}$ show trends in age-standardized mortality from all causes during the same time-period. Because the data come from two different sources, with subtle differences in data and methods, the trend lines have not been connected. The three trend-lines represent the life expectancy values corresponding to the first, second and third quartiles, respectively. In the first sub-period, all three trend lines declined spectacularly, both among men and among women, but at first this decline was more rapid in some countries than in others, as is clear from the divergence between the trend lines. This divergence occurred both in Europe as a whole and in Western Europe only. In the second sub-period we see the trend lines starting to decline and diverge again, but in this case the divergence is not seen in Western Europe, so must again be due to developments in Central and Eastern Europe.

The first episode of widening occurred in a period of rapid mortality decline, mainly because of declining mortality from infectious diseases, as can be seen in Fig. 3. The trend lines for the first and third quartile in Fig. 3a-b show that some countries lagged behind in their decline of mortality from infectious diseases, which led to a substantial gap in mortality from these causes. Inspection of the underlying data shows that the countries lagging behind were either in Southern Europe (represented in our data-set by Spain, Portugal, Greece) or in Central and Eastern Europe (represented in our data-set by Czechoslovakia, Hungary, Bulgaria) (results not shown). The second episode of widening occurred in a period of beginning mortality decline, driven by declining mortality from cardiovascular disease. Figures $3 c-d$ show that there were substantial differences between countries in the starting year of mortality 

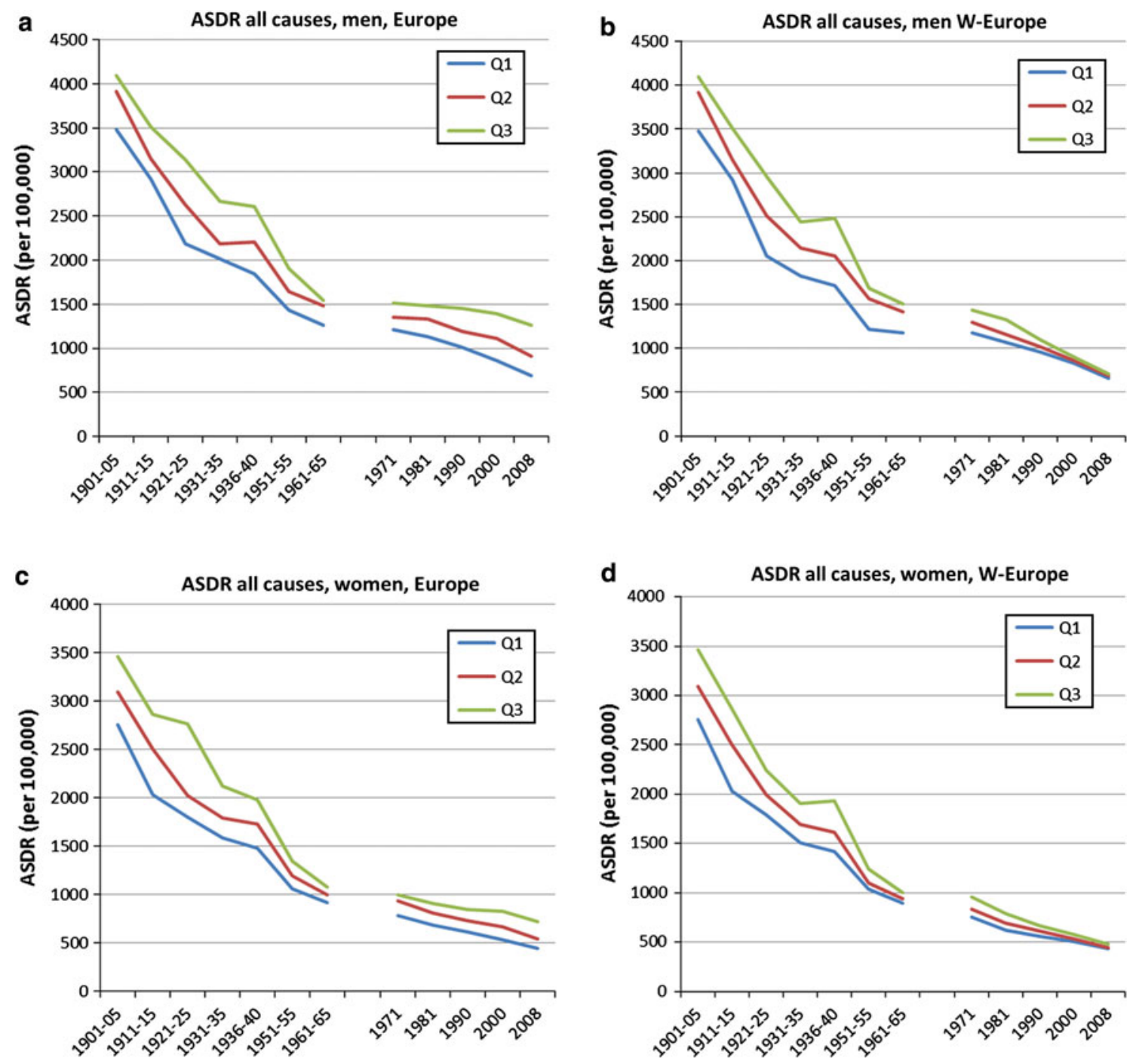

Fig. 2 Variation in age-standardized death rates in Europe, 1901-2008, all causes, by gender a Quartile values, Europe, men b Quartile values, Western Europe, men c Quartile values, Europe, women d Quartile values, Western Europe, women. Notes: ASDR

decline for cardiovascular diseases, and that mortality still went up in some countries while it already declined in some others, particularly among men. The countries lagging behind were all in Central and Eastern Europe (results not shown). This led to a large gap in mortality from these causes.

As Table 2 shows, absolute differences between countries in national income have increased throughout the study-period. Relative differences, on the other hand, were more or less stable until 1980, and then climbed to reach a peak in 2000. Unlike previous rises of the gap in income, the recent rise is partly due to declining income in some parts of Europe (not shown in the table). The association between national income and life expectancy has always been positive. The strength of the association (as measured

age-standardized death rate, $Q 1$ age-standardized death rate at first quartile, $Q 2$ age-standardized death rate at second quartile or median, Q3 age-standardized death rate at third quartile. IQR = Inter-quartile range or Q3-Q1

by the slope parameter) increased between 1900 and 1920, and then slowly declined to reach much lower values in 1980, after which the strength of the association has remained stable. The most recent slope parameter, for 2008 , still indicates that for each $\mathrm{I} \$ 1000$ increase in national income, life expectancy rises by 0.54 (men) or 0.37 (women) years. In terms of correlation coefficients the relation has become even stronger to reach similar levels as those seen before World War II in recent decades.

Figure 4a shows that changes in the range of variation of Gross Domestic Product (GDP), and/or in the relation between GDP and life expectancy, are a reasonably good predictor of convergence and divergence of life expectancy. Both episodes of widening can to some extent be 'predicted' on the basis of a simple regression of life expectancy on 

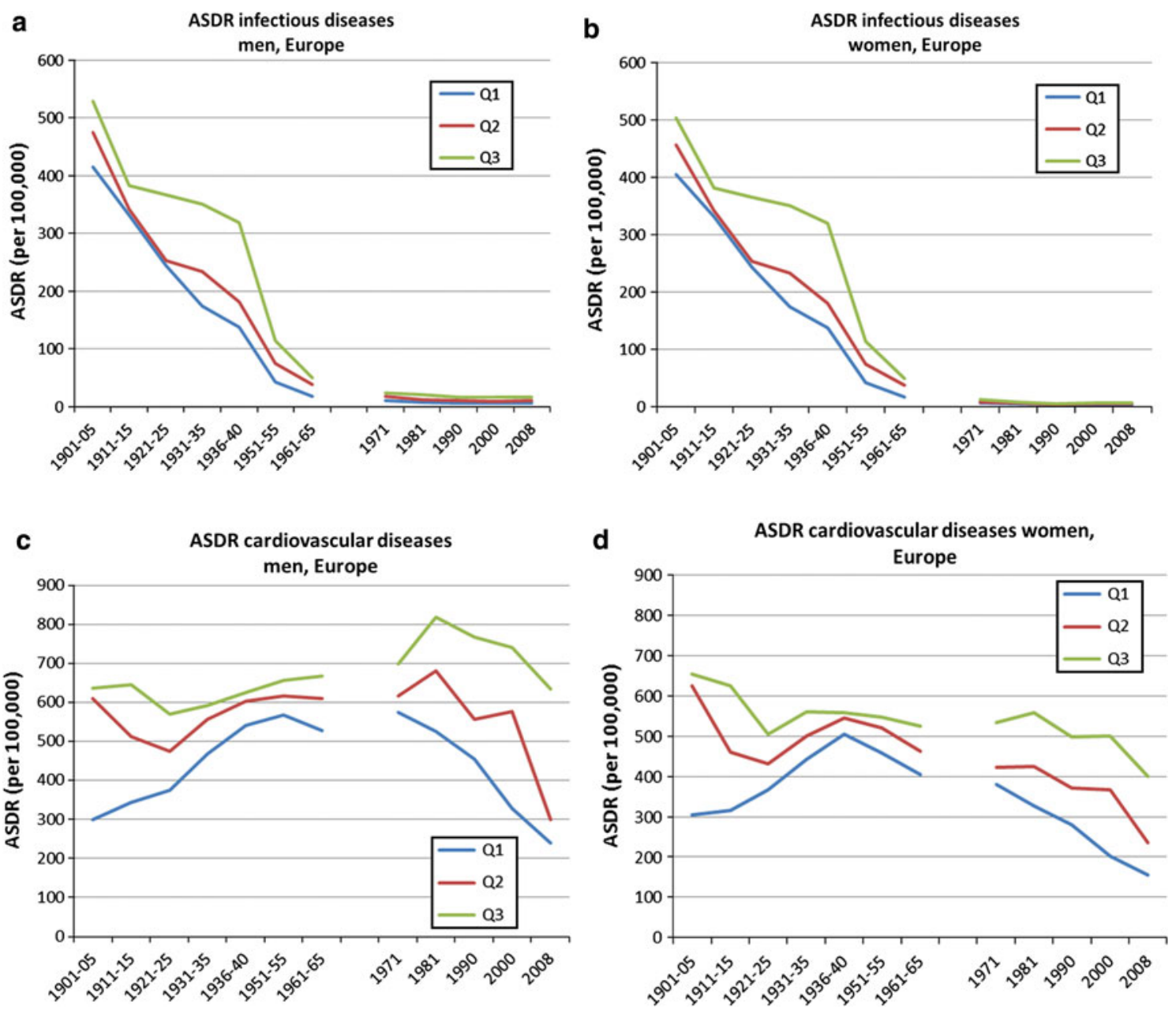

Fig. 3 Variation in age-standardized death rates in Europe, 1901-2008, infectious and cardiovascular diseases, by gender a Infectious diseases, men b Infectious diseases, women c Cardiovascular diseases, men d Cardiovascular diseases, women. Notes: ASDR

age-standardized death rate, $Q 1$ age-standardized death rate at first quartile, $Q 2$ age-standardized death rate at second quartile or median, Q3 age-standardized death rate at third quartile

Table 2 Variation in national income and association with life expectancy in Europe, 1900-2008

\begin{tabular}{lcccccccccccc}
\hline & 1900 & 1910 & 1920 & 1930 & 1939 & 1950 & 1960 & 1970 & 1980 & 1990 & 2000 & 2008 \\
\hline GDP & & & & & & & & & & \\
Average GDP & 2158 & 2479 & 2737 & 3170 & 3859 & 3893 & 5539 & 7620 & 10614 & 10341 & 11294 & 14668 \\
IQR of GDP (Q3-Q1) & 1550 & 1666 & 1911 & 2474 & 2769 & 3274 & 4347 & 4691 & 8130 & 10286 & 15156 & 14532 \\
Association with life expectancy, men & & & & & & & & & & \\
Correlation coefficient & 0.31 & 0.54 & 0.73 & 0.83 & 0.83 & 0.81 & 0.50 & 0.48 & 0.63 & 0.61 & 0.71 & 0.78 \\
Regression coefficient & 1.44 & 3.48 & 4.70 & 3.46 & 3.74 & 1.80 & 0.65 & 0.49 & 0.47 & 0.48 & 0.51 & 0.54 \\
Regression coefficient, s.e. & 1.33 & 1.55 & 1.26 & 0.56 & 0.65 & 0.29 & 0.15 & 0.13 & 0.09 & 0.08 & 0.06 & 0.08 \\
Association with life expectancy, women & & & & & & & & & \\
Correlation & 0.41 & 0.59 & 0.73 & 0.85 & 0.88 & 0.85 & 0.68 & 0.59 & 0.77 & 0.71 & 0.79 & 0.84 \\
Regression coefficient & 2.21 & 4.17 & 4.82 & 3.50 & 3.28 & 1.84 & 0.82 & 0.60 & 0.53 & 0.43 & 0.37 & 0.37 \\
Regression coefficient, s.e. & 1.48 & 1.64 & 1.29 & 0.521 & 0.45 & 0.25 & 0.14 & 0.12 & 0.06 & 0.05 & 0.04 & 0.04 \\
\hline
\end{tabular}

GDP gross domestic product in 1990 international dollars per capita, IQR inter-quartile range, Regression coefficient slope parameter (in years per 1000 dollars), s.e. standard error 

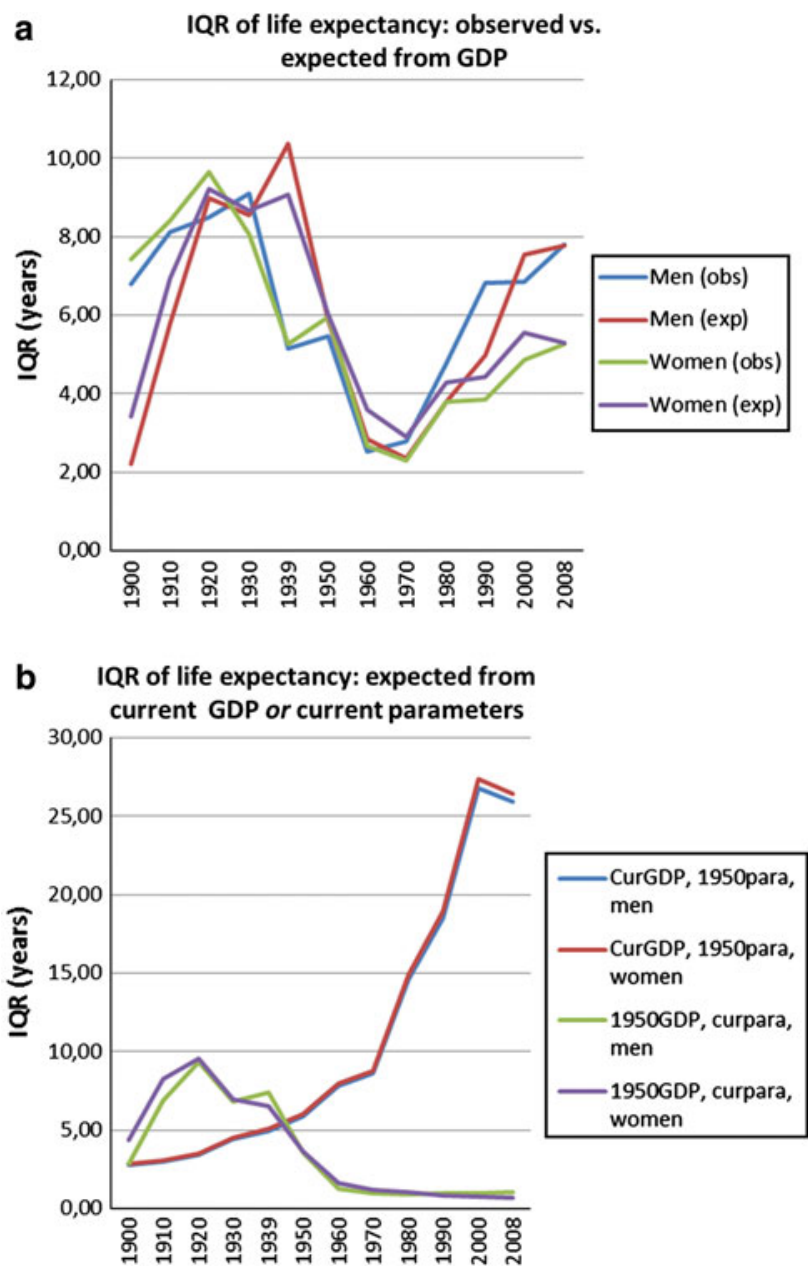

Fig. 4 Variation in observed life expectancy versus variation in expected life expectancy in Europe, 1900-2008, by gender a. Observed life expectancy versus life expectancy expected on the basis of current GDP and current GDP-life expectancy relation b Life expectancy expected on the basis of 1950 GDP and current GDP-life expectancy relation, and life expectancy expected on the basis of current GDP and 1950 GDP-life expectancy relation

national income. The underlying mechanisms, however, are rather different. The increase in the inter-quartile range of life expectancy in the first decades of the 20th century can be predicted from the change in the relation between GDP and life expectancy: even with each country's GDP held constant, the expected values of life expectancy still rise substantially in this period (Fig. 4b). This is due to the fact that the association between GDP and life expectancy, as expressed in the slope parameter, becomes stronger during this time-period (Table 2). On the other hand, the increase of the inter-quartile range of life expectancy after 1970 appears to be primarily due to a rising gap in national income between countries: even with the regression parameters held constant, the expected values of life expectancy rise dramatically in this period (Fig. 4b). This is explained by the fact that since
1980 the inter-quartile range of GDP has increased enormously (Table 2). It is only because the association with GDP has become weaker over time that the actual interquartile range of life expectancies in 2008 is between 5 and 8 years (Table 1), not 26 years (Fig. 4b).

\section{Discussion and conclusions}

Summary of main findings

During the first decades of the 20th century, variation in life expectancy in Europe increased to reach peak values around 1920, then decreased to reach its lowest values in 1960 (among men) and 1970 (among women), and finally increased strongly again. The first widening occurred in a period with rapid declines in age-standardized mortality, and was due to less rapid declines in mortality in Southern and Central and Eastern Europe, particularly from infectious diseases. The second widening occurred in a period of renewed mortality decline, and was due to stagnating or increasing mortality in Central and Eastern Europe, particularly from cardiovascular diseases. During the whole study-period differences between countries in national income increased. The first widening of inequalities in life expectancy coincided with an increasing strength of the national income-life expectancy relation, and the second with an exceptionally strong rise of between-country differences in national income.

\section{Limitations}

A major strength of our study is that we have brought together all European life expectancy data with documented validity. The downside of this is that there are gaps in the available data. Before World War II, our coverage of Europe is much more complete for Western than for Central and Eastern Europe, both with life expectancy data and with data on mortality by cause of death. For this period, the life expectancy dataset only partly covers the (then) Soviet Union, and the cause-of-death dataset does not cover the Soviet Union at all. The analysis of data for Western Europe only, however, allowed us to separate out the trends in Western Europe from those in Central and Eastern Europe, and clearly showed that the first episode of divergence probably occurred in the whole of Europe, while the second episode was limited to Central and Eastern Europe.

Period life expectancy, the metric we used in our analyses, is a commonly used, reliable and easily interpretable summary measure of the mortality conditions applying to a 
particular point in time [29]. It should, however, not be interpreted as an estimate of the number of years that babies born in a particular year can expect to live. Other limitations of this measure are that tempo effects can distort the measurement of life expectancy in times of rapidly declining or increasing mortality rates [30,31], and that at lower rates of mortality larger and larger declines are necessary for one unit increase in life expectancy [29]. Despite the fact that the latter phenomenon drives life expectancy to convergence, we observed a substantial widening over recent decades, caused by a substantial widening of the underlying mortality rates (Fig. 2).

Our analysis of cause-of-death data used routinely registered information which is of uncertain validity, particularly in the earlier parts of the study-period. Because our analysis was limited to two broad groups of causes of death, however, the results are unlikely to be seriously biased. Because we used a careful reconstruction of the code numbers pertaining to infectious and cardiovascular diseases in previous editions of the International Classification of Diseases [25], changes in classification between editions are also unlikely to have affected our results.

Our analysis of the association between life expectancy and national income is based on cross-sectional data, and we cannot assume that these associations are a good representation of the underlying causal relationships. There may be confounding by third factors that are associated with both national income and life expectancy, such as levels of education [32], or there may be bias from reverse causality if increased life expectancy, or improved population health generally, contributes to a higher national income [33-35]. That caution in interpretation is needed is also clear from the fact that only part of the rise in life expectancy between successive points in time can be explained from rises in national income and the cross-sectional association between national income and life expectancy [36], and that longitudinal associations between changes in national income and changes in life expectancy are usually weaker than cross-sectional associations [37]. Nevertheless, there is scientific consensus that economic prosperity is one of the most important determinants of population health [38], and use of these associations for exploratory purposes as in this paper is certainly warranted. Remarkably, and in contrast to what is seen in world-wide analyses also covering low-income countries $[36,39,40]$, the relation between national income and life expectancy continues to be approximately linear within Europe [41], as can also indirectly be inferred from the high correlation between GDP and life expectancy even in 2008 (Table 2).
Interpretation

Our results suggest that both episodes of widening differences in life expectancy can plausibly be seen as resulting from differences between countries in timing of epidemiologic transitions. The first episode was partly due to earlier or more rapid decline of infectious disease mortality in Northwestern Europe, as compared to Southern and Central and Eastern Europe. The second episode was partly due to an earlier decline of cardiovascular disease mortality in Western Europe, as compared to Central and Eastern Europe.

Although this suggests a common explanation of both episodes, at least at a very general level, we also found two important differences between the two episodes which cast doubt on a common explanation. The second episode is partly due to rising mortality in some countries (which we did not observe in the first episode), and the second episode appears to have been fuelled by a rising gap in income (while the first episode could statistically be attributed mainly to an increase in the strength of the association between national income and life expectancy).

The first difference between both episodes, if seen in isolation from the second difference, could be due to the different time-windows in which they were observed. The first episode occurred during the last decades of infectious disease mortality decline, and there may have been earlier instances (or an earlier start) of widening disparities in life expectancy during the 19th century, unobserved in our study, that were due to rising mortality in some countries and declining mortality in others. An unpublished paper analyzing European trends in life expectancy since the middle of the 19th century suggests that there was an earlier episode of widening around 1875 [42], and some studies have found that 19th century urbanization may have caused a rise in mortality in some countries [43]. The second episode occurred during what may in the future turn out to be the first decades of cardiovascular disease mortality decline, and during later stages of this transition we may see a further widening primarily due to differential mortality decline.

The second difference, however, does indicate that these two episodes have at least a partly different explanation. The first episode coincided with a change in the association between national income and life expectancy, in which the marginal benefits of a higher national income in terms of increased life expectancy seem to have become much larger. In 1900, a I $\$ 1000$ higher national income was associated with 1.4 (men) to 2.2 (women) years of extra life expectancy, and this difference had more than doubled to 4.7 and 4.8 years respectively in 1920 (Table 2). This suggests that important technical or organizational innovations had taken place that lowered the cost or raised the 
effectiveness of health interventions. Historical studies have documented that innovations implemented in this period were part of the public health revolution (clean drinking water and sanitation, improvements in housing and working conditions, mother and child care, personal hygiene, ...) $[28,44,45]$. This may have allowed countries with a higher national income to derive much more health benefit from their higher income in this period, with poorer countries following as soon as their rising incomes allowed them to.

The second episode of widening disparities in life expectancy, however, coincided with a rising gap in income which was caused by the economic stagnation and subsequent impoverishment of a part of Europe preceding and following the collapse of the Soviet Union (Table 2) $[12,26]$. Although this relative and then absolute economic downturn was temporary, it laid the basis for an enormous gap in national income that, as our results suggest, in itself may be sufficient to explain the life expectancy gap (Fig. 4a). This was not a simple delay in epidemiologic transition but an actual setback (Figs. 1 and 3c). Whether these widening disparities in life expectancy were really caused by widening income disparities cannot be inferred from this analysis. As mentioned in the Introduction, unfavorable trends in mortality in Central and Eastern Europe have been attributed to a range of factors linked to the political and economic situation in the communist and post-communist era, such as dietary problems, excessive alcohol consumption, lack of access to adequate health care, unemployment, poverty and psychosocial stress [8-12]. All of these may partly have been determined by stagnating or declining national incomes, or, alternatively, the latter may only act as a marker for unfavorable social trends underlying both the economic and health performance of communist and post-communist countries.

The absence of a change in the strength of the association between national income and life expectancy suggests that mortality decline in recent decades was not primarily driven by innovations that increased the marginal benefits of a higher national income. Instead, innovations appear to have required investments that were only possible in countries with rapidly rising incomes, like those in Western Europe. This is compatible with a substantial role of medical care in the decline of cardiovascular disease mortality [46-48]. In an additional analysis we therefore tested the hypothesis that part of the widening gap in life expectancy is due to widening between-country differences in medical care, by studying trends in health care expenditure.

Reliable data on health care expenditure in Central and Eastern Europe are only available since 1995, and show that the inter-quartile range of health care expenditure as a percentage of national income in Europe as a whole rose from $2.4 \%$ in 1995 to $2.9 \%$ in 2008 (data from the World Health Organization Health for All Database (http://data.euro.who.int/hfadb/)). This represents a huge increase in absolute disparities in health care expenditure (in Euros per capita) (cf. Table 2). While this appears to confirm our hypothesis, the same dataset shows that between-country differences in smoking, as indicated by the inter-quartile range of the number of cigarettes smoked per capita per year, also increased substantially (results not shown). Further study of the explanation of the widening gap in life expectancy in Europe, taking into account the changing relation with economic factors [49], is therefore necessary.

What can be done to close the current health divide within Europe? A recent review commissioned by the World Health Organization (WHO) recommends action on health care as well as on lifestyle factors, but moves beyond these immediate causes to also address some of the underlying social, economic and political determinants. Examples of policy actions believed to help improving health in Central and Eastern Europe include reducing poverty and strengthening social protection, more stringent tobacco and alcohol control, and ensuring universal health care coverage [50]. International collaboration, supported by WHO and the European Union, will be needed to promote mutual learning and encourage sharing of resources.

\section{Conclusions}

Despite some similarities, differences between both episodes of widening differences in life expectancy cast doubt on the idea that they have similar explanations. Interpreting the recent widening in terms of a 'normal' delay of epidemiological transitions related to the necessary diffusion of innovations across the European subcontinent, carries the risk that one would see this divergence as a phenomenon that will automatically disappear when a natural process of diffusion is allowed to continue. Our results suggest that this may well be a romantic illusion. Instead, the current episode of widening differences in life expectancy is an alarming phenomenon that should be a main focus of European policy making.

Acknowledgments The author thanks Dr. France Meslé and Prof. Jacques Vallin (Institut National des Etudes Démographiques, Paris, France) and Dr. Domantas Jasilionis (Max Planck Institute for demographic Research, Rostock, Germany) for sharing some of their data with him. The author thanks Caspar Looman for carrying out the regression analysis that provided the parameters for calculating expected life expectancies, and Wilma Nusselder and Frederik Peters for providing interesting comments on a previous version of this paper.

Conflict of interest The author declares that he has no conflicts of interest. 


\section{Appendix}

ICD-codes for Fig. 3

\begin{tabular}{llll}
\hline $\begin{array}{l}\text { ICD codes } \\
\text { ICD Revision }\end{array}$ & Start-year & Infectious diseases & Cardiovascular diseases \\
\hline 1 & 1901 & $1-9,11,12,14-24,26-38,61.2,62,67,72,107,111$ & $64-66,77-86,142$ \\
2 & 1909 & $1-9,11,12,14-25,28-35,37,38,61$ A,B, 62, 67, 112, 121, 106, 107, 164 & $64-66,77-83,84 \mathrm{~B}, 85,142$ \\
3 & 1920 & $1-10,12-14,16-42,72,76,115,116,121,130,175$ & $74,75,83,87-96,151$ \\
4 & 1929 & $1-10,12-44,80,83,177$ & $82,90-103,111: 2$ \\
5 & 1938 & $1-32,34-43,44 a, c, d, 177$ & $83,90 b, 91-103,111 \mathrm{a}$ \\
6 & 1948 & $1-43$ & $70,80-86$ \\
7 & 1955 & $1-43$ & $70,80-86$ \\
8 & 1965 & $1,4,6-44$ & $81-88$ \\
9 & 1979 & $001-139$ & $390-459$ \\
10 & 1999 & A00-A99, B00-B99 & I00-I99
\end{tabular}

\section{References}

1. Vallin J, Meslé F, Adamets S, Pyrozhkov S. A new estimate of Ukrainian population losses during the crises of the 1930s and 1940s. Popul Stud (Camb). 2002;56(3):249-63. (Epub 2003/01/ $30)$.

2. White M. Historical Atlas of the Twentieth Century. 1998 [07-072012]; Available from: http://users.erols.com/mwhite28/20centry. htm.

3. McMichael AJ, McKee M, Shkolnikov V, Valkonen T. Mortality trends and setbacks: global convergence or divergence? Lancet. 2004;363(9415):1155-9. (Epub 2004/04/06).

4. Leon DA. Trends in European life expectancy: a salutary view. Int J Epidemiol. 2011;40(2):271-7. (Epub 2011/03/19).

5. Moser K, Shkolnikov V, Leon DA. World mortality 1950-2000: divergence replaces convergence from the late $1980 \mathrm{~s}$. Bull World Health Organ. 2005;83(3):202-9. (Epub 2005/03/31).

6. Zatonski W. Closing the health gap in the European Union. Warsaw: Maria Sklodowska-Curie Memorial Cancer Center and Institute of Oncology; 2008. p. 227.

7. Robine JM, Le Roy S, Jagger C. Changes in life expectancy in the European Union since 1995: similarities and differences between the 25 EU countries. n.p.: European Health Expectancy Monitoring Unit (EHEMU); n.d.

8. Rechel B, McKee M. Health reform in central and eastern Europe and the former Soviet Union. Lancet. 2009;374(9696):1186-95. (Epub 2009/10/06).

9. Leon DA, Shkolnikov VM, McKee M. Alcohol and Russian mortality: a continuing crisis. Addiction. 2009;104(10):1630-6. (Epub 2009/08/18).

10. McKee M. Public health in Central and Eastern Europe and the former Soviet Union. In: Beaglehole R, Bonita R, editors. Global public health a new era. Oxford: Oxford University Press; 2009. p. 101-21.

11. Pomerleau J, Lock K, McKee M. The burden of cardiovascular disease and cancer attributable to low fruit and vegetable intake in the European Union: differences between old and new Member States. Public Health Nutr. 2006;9(5):575-83. (Epub 2006/08/23).

12. Stuckler D, King L, McKee M. Mass privatisation and the postcommunist mortality crisis: a cross-national analysis. Lancet. 2009;373(9661):399-407. (Epub 2009/01/20).

13. Omran AR. The epidemiologic transition. A theory of the epidemiology of population change. Milbank Mem Fund Q. 1971;49(4):509-38. (Epub 1971/10/01).
14. Omran AR. The epidemiologic transition theory A preliminary update. J Trop Pediatr. 1983;29(6):305-16. (Epub 1983/12/01).

15. Riley JC. Rising life expectancy. A global history. Cambridge: Cambridge University Press; 2001. p. 243.

16. McKeown TF. The origins of human disease. Oxford: Blackwell; 1988. p. 233.

17. Trowell HC, Burkitt DP, editors. Western diseases, their emergence and prevention. Cambridge (Massachusetts): Harvard University Press; 1981.

18. Olshansky SJ, Ault AB. The fourth stage of the epidemiologic transition: the age of delayed degenerative diseases. Milbank Q. 1986;64(3):355-91. (Epub 1986/01/01).

19. Vallin J, Mesle F. Convergences and divergences in mortality. A new approach to health transition. Demographic research. 2004;SPECIAL COLLECTION 2, ARTICLE 2:11-44.

20. Meslé F, Vallin J. Diverging trends in female old-age mortality: the United States and the Netherlands versus France and Japan. Popul Dev Rev. 2006;32(1):123-45.

21. Rogers EM. Diffusion of innovations. Glencoe: Free Press; 1962.

22. Vallin J, Meslé F. The segmented trend line of highest life expectancies. Popul and Dev Rev. 2009;35(1):159-87.

23. Meslé F, Shkolnikov V, Vallin J. Mortality by cause in the USSR in 1970-1987: the reconstruction of time series. Eur J Popul. 1992;8(4):281-308. (Epub 1992/01/01).

24. Duthé G, Badurashvili I, Kuyumjyan K, Meslé F, Vallin J. Mortality in the Caucasus: An attempt to re-estimate recent mortality trends in Armenia and Georgia. Demographic research. 2010;22:691-732.

25. Alderson M. International mortality statistics. New York: Facts on File; 1981.

26. Maddison A. The world economy: historical statistics. Paris: Organisation of Economic Cooperation and Development; 2003.

27. Preston SH. The changing relation between mortality and level of economic development. Population Studies, 29(2), July 1975. Int J Epidemiol. 2007;36(3):484-90. (Epub 2007/06/07).

28. Preston SH. Mortality patterns in national populations, with special reference to recorded causes of death. New York: Academic Press; 1976.

29. Preston SH, Heuveline P, Guillot M. Demography. Measuring and modeling population process. Oxford: Blackwell; 2001.

30. Bongaarts J, Feeney G. How long do we live. Popul Dev Rev. 2002;28(1):13-29.

31. Luy M. Mortality tempo-adjustment: an empirical application. Demographic Research. 2006;15(21):561-90. 
32. Caldwell JC. Routes to low mortality in poor countries. Population and Development Review. 1986;12(2):171-220.

33. Fogel RW. The escape from hunger and premature death, 1700-2100. Europe, America, and the third world. Smith R, de Vries J, Johnson P, Wrightson K, editors. Cambridge: Cambridge University Press; 2004. p. 191.

34. Acemoglu D, Johnson S. Disease and development: the effect of life expectancy on economic growth. Cambridge: National Bureau for Economic Research; 2006.

35. Swift R. The relationship between health and GDP in OECD countries in the very long run. Health Econ. 2011;20(3):306-22. (Epub 2010/03/11).

36. Preston SH. The changing relation between mortality and level of economic development. Population Studies. 1975;29(2):231-48. (Epub 2007/06/07).

37. Bloom DE, Canning D. Commentary: the Preston Curve 30 years on: still sparking fires. Int J Epidemiol. 2007;36(3):498-9. (discussion 502-3. Epub 2007/06/07).

38. Caldwell JC. Mortality in relation to economic development. Bull World Health Organ. 2003;81(11):831-2. (Epub 2004/02/06).

39. Bank World. World development report 1993. Washington: World Bank; 1993.

40. Deaton A. Health in an age of globalization. Cambridge: National Bureau for Economic Research; 2004.

41. Mackenbach JP, Looman CWN. Life expectancy and national income in Europe, 1900-2008: an update of Preston's analysis. International Journal of Epidemiology. Submitted for publication.

42. Robine JM, Le Roy S, Jagger C, team tE. Changes in life expectancy in the European Union since 1995: similarities and differences between the $25 \mathrm{EU}$ countries. n.d.
43. Floud R, Fogel RW, Harris B, Chul Hong S. The changing body. Health, nutrition, and human development in the western world since 1700. Cambridge: Cambridge University Press; 2011.

44. Szreter S. Rethinking McKeown: the relationship between public health and social change. Am J Public Health. 2002;92(5):722-5. (Epub 2002/05/04).

45. Ward JW, Warren C, editors. Silent victories. The history and practice of public health in twentieth-century America. Oxford: Oxford University Press; 2007.

46. Cutler DM, Rosen AB, Vijan S. The value of medical spending in the United States, 1960-2000. N Engl J Med. 2006;355(9):920-7. (Epub 2006/09/01).

47. Goldman L, Cook EF. The decline in ischemic heart disease mortality rates. An analysis of the comparative effects of medical interventions and changes in lifestyle. Ann Intern Med. 1984;101(6):825-36. (Epub 1984/12/01).

48. Bots ML, Grobbee DE. Decline of coronary heart disease mortality in The Netherlands from 1978 to 1985: contribution of medical care and changes over time in presence of major cardiovascular risk factors. J Cardiovasc Risk. 1996;3(3):271-6. (Epub 1996/06/01).

49. Ezzati M, Vander Hoorn S, Lawes CM, Leach R, James WP, Lopez $\mathrm{AD}$, et al. Rethinking the "diseases of affluence" paradigm: global patterns of nutritional risks in relation to economic development. PLoS Med. 2005;2(5):e133. (Epub 2005/05/27).

50. Marmot M, Allen J, Bell R, Bloomer E, Goldblatt P. WHO European review of social determinants of health and the health divide. Lancet. 2012;380(9846):1011-29. (Epub 2012/09/12). 